doi.org/ro.51891/rease.v7i8.1925

\title{
VISÃO DA ENFERMAGEM PERANTE ALTERAÇÕES CARDIOVASCULARES E A COVID-ı:: COMPLICAÇÕES E RISCOS
}

\author{
NURSING VIEW TOWARDS CARDIOVASCULAR CHANGES AND COVID-ig: \\ COMPLICATIONS AND RISKS
}

\section{VISIÓN DE ENFERMERÍA HACIA LOS CAMBIOS CARDIOVASCULARES Y EL COVID-I9: COMPLICACIONES Y RIESGOS}

\author{
Bruno Henrique Souza Izidório ${ }^{1}$ \\ Ariádna Emerick Vieira ${ }^{2}$ \\ Ariane Kesse Lima Almeida ${ }^{3}$ \\ Ana Carolina Moreira Filete 4 \\ Márcia Dutra Aguiar ${ }^{5}$
}

RESUMO: Objetivo: Traçar os riscos e as complicações desencadeadas pela Covid-ı9 no sistema cardiovascular preparando assim os profissionais ou graduandos na área da saúde para desenvolverem um olhar clínico sobre as consequências da Covid nesse sistema. Método: O estudo trata-se de uma revisão bibliográfica do tipo descritiva. Para sua realização foi feita uma seleção de publicações no SciELO e revistas de peso na cardiologia, no intervalo 2015-2021. Conclusão: Pacientes que tem doença cardiovascular apresentam prognóstico pior, bem como os que estão presentes em grupo de risco tem o índice de mortalidade nove vezes maior. As principais complicações evidenciadas foram: arritmia, lesão cardíaca, aumento dos fatores pró-coagulantes, miocardite, insuficiência cardíaca aguda e trombose.

Descritores: Covid-ı9. Doenças cardiovasculares. Enfermagem.

ABSTRACT: Objective: To trace the risks and complications triggered by Covid-19 in the cardiovascular system, thus preparing professionals or undergraduates in the health area to develop a clinical look at the consequences of Covid in this system. Method: The study is a descriptive bibliographic review. For its realization, a selection of publications in SciELO and weight magazines in cardiology was made, in the 2015-2021 interval. Conclusion: Patients with cardiovascular disease have a worse prognosis, as well as those who are present in a risk group have a mortality rate nine times higher. The main complications evidenced were: arrhythmia, cardiac injury, increased procoagulant factors, myocarditis, acute heart failure and thrombosis.

\footnotetext{
I Enfermeiro Mestrando pelo Centro Universitário Augusto Motta (UNISUAM), pós-graduação em Saúde da Família pela Faculdade Venda Nova do Imigrante (FAVENI), graduação em Enfermagem Faculdade do Futuro (FAF), professor da Faculdade do Futuro (FAF), brunoizidorioo@outlook.com.

${ }^{2}$ Acadêmica do curso de graduação de Enfermagem da Faculdade do Futuro, ariadnaemerickenf@outlook.com.

${ }_{3}^{3}$ Acadêmica do curso de graduação de Enfermagem da Faculdade do Futuro, ariane-kesse@hotmail.com.

${ }_{4}^{4}$ Acadêmica do curso de graduação de Enfermagem da Faculdade do Futuro, carolfileteg8@gmail.com.

5 Acadêmica do curso de graduação de Enfermagem da Faculdade do Futuro, aguiardutraenf@outlook.com.
} 
Descriptors: Covid-ı. Cardiovascular diseases. Nursing.

RESUMEN: Objetivo: rastrear los riesgos y complicaciones desencadenadas por Covid-i9 en el sistema cardiovascular, preparando así a profesionales o estudiantes universitarios en el área de la salud para desarrollar una visión clínica de las consecuencias de Covid en este sistema. Método: el estudio es una revisión bibliográfica descriptiva. Para su realización, se realizó una selección de publicaciones en SciELO y revistas de peso en cardiología, en el intervalo 2015-2021. Conclusión: Los pacientes con enfermedad cardiovascular tienen un peor pronóstico, así como aquellos que están presentes en un grupo de riesgo tienen una tasa de mortalidad nueve veces más alto. Las principales complicaciones evidenciadas fueron: arritmia, lesión cardíaca, aumento de los factores procoagulantes, miocarditis, insuficiencia cardíaca aguda y trombosis.

Descriptores: Covid-ı. Enfermedades cardiovasculares. Enfermería.

\section{INTRODUÇÃO}

Atualmente estamos passando por um período histórico caracterizado pelo surgimento do Coronavírus, mais precisamente desde dezembro de 2019. A doença causada por esse vírus que é cientificamente conhecido como SARS-COV-2 foi nomeada pela Organização Mundial da Saúde (OMS) como Covid-I9, surgindo na cidade de Wuhan, China (FERRARI, 2020). Classificado como Betacoronavírus do mesmo subgênero da síndrome da insuficiência respiratória aguda grave, tem $96,2 \%$ de identificação genética com o betaCoV/bat/Yunnan que é um vírus isolado dos morcegos (STRABELLI; UIP 2020).

Sua principal manifestação no corpo humano se assemelha a outras viroses respiratórias, porém pode evoluir até uma pneumonia grave. Seus sintomas se caracterizam como febre, tosse geralmente seca, dor de cabeça, e em casos mais graves manifesta-se dispnéia sendo o sintoma mais reconhecido, sangramento pulmonar, linfopenia grave, e insuficiência renal (LIMA,2020).

Apesar da sintomatologia da doença ser relacionada ao trato respiratório o coronavírus pode também afetar outros sistemas como o cardiovascular. Por mais que não tenha evidências específicas sobre a relação do Covid com esse sistema, relacionam-se arritmias, lesões cardíacas agudas, taquicardia e alta carga de doenças cardiovasculares concomitantes aos infectados, principalmente os que necessitavam de cuidados intensivos. Alterações estas que podem associar-se a resposta inflamatória sistêmica causada pelo coronavírus (FERRARI, 2020). 
O Brasil confirmou seu primeiro caso de coronavírus em São Paulo no dia 26 de fevereiro de 2020 com um paciente do sexo masculino com 6r anos de idade (BRASIL, 2020). Baseando-se nisso e que o Brasil como a maioria dos países passa pela transição demográfica evidenciando o envelhecimento da população e tendo como sua principal causa de morte doenças do sistema cardiovascular, verifica-se logo que o país enfrenta dois grandes fatores de risco para o aumento da mortalidade pela Covid-ı9 (COSTA J., et al 2020).

Com isso evidencia-se a necessidade de acompanhamento e monitorização do sistema cardiovascular do paciente infectado pela Covid-ı de modo que possam ser verificados os riscos e complicações desencadeadas, além de serem traçadas estratégias para minimização de danos através do uso desse conhecimento.

Por meio disso, o estudo em questão tem como objetivo traçar os riscos e as complicações desencadeadas pela Covid-ı9 no sistema cardiovascular preparando assim os profissionais ou graduandos na área da saúde para desenvolverem um olhar clínico sobre as consequências da Covid nesse sistema.

Baseado no que foi apresentado, levantam-se as seguintes hipóteses:

- As alterações cardiovasculares causadas pela Covid-ı influenciam diretamente no prognóstico e recuperação dos pacientes;

- O prognóstico e recuperação do paciente independem de qualquer forma de complicações cardiovasculares causadas pela Covid-ı.

- As alterações cardiovasculares causadas pela Covid-ı́ não têm relação com o prognóstico e com a recuperação do paciente;

Para alcançar esses objetivos questiona-se qual o impacto que a infecção viral do covid-ı9 realiza sobre o sistema cardiovascular e se portadores de doenças nesse sistema correm mais risco, bem como as complicações que estas alterações podem causar e seu reflexo sobre prognóstico do paciente.

\section{MÉTODO}

Os autores Prodanov e Freitas, (2013) citam que a Metodologia é um nível aplicado que examina, descreve e avalia métodos e técnicas de pesquisa que possibilitam a coleta e o processamento de informações, visando ao encaminhamento e à resolução de problemas e/ou questões de investigação. 
Marconi e Lakatos, (2013) afirmam que a utilização de métodos científicos é a continuidade de informações que possam auxiliar na interpretação de uma pesquisa, mas não somente, podendo, ainda, ser passível de uso no cotidiano. O método é a ciência que se transforma.

O presente estudo trata-se de uma pesquisa integrativa, qualitativa, de carácter descritivo.

. Para sua realização foi realizada uma seleção de publicações no SciELO e revistas de peso na cardiologia, no intervalo 2015-2021. Foram utilizados os seguintes descritores: Os materiais em estudo relacionavam a Covid-ı9 e as alterações no sistema cardiovascular e o que esta pode causar. Assim, foi realizada a análise da pesquisa, selecionando as informações precisas de maior relevância para a conclusão deste estudo.

\section{REVISÃO BIBLIOGRÁFICA}

A Covid-I9 é causada por um vírus RNA que se liga ao receptor da enzima conversora de angiotensina 2 (ECA 2). Esta enzima é presente em maior parte em algumas células pulmonares, mas também é presente no epitélio intestinal, endotélio vascular e rins além de ser muito liberada pelo coração em casos de ativação excessiva do sistema reninaangiotensina como na hipertensão, insuficiência cardíaca congestiva, e arteriosclerose (ASKIN, TANRIVERDI, ASKIN, 2020).

Além disso, é transmitido por meio de gotículas respiratórias e contato, com um período de incubação que varia de 5 a 12 dias, devendo como forma preventiva reforçar medidas de higiene como: lavagem das mãos com água e sabão; uso de álcool gel e máscara; evitar locais de aglomeração e cobrir boca ao tossir ou espirrar (COSTA J., et al 2020).

De alta disseminação com nível de transmissão 3-I, em que I infectado contamina em torno de 3 pessoas, possui cerca de $85 \%$ dessa disseminação causada por pessoas assintomáticas. Devido a esta taxa e alta disseminação, esta doença é classificada como pandemia no dia II de março de 2020 pela OMS (COSTA I, et al 2020).

Após a apresentação dos sintomas já descritos, o diagnóstico padrão-ouro da Covid é realizado através da detecção do ácido nucleico em zaragota nasal, amostras do sistema respiratório pela detecção de respostas em cadeia polimerase (RCP) e amostras de garganta (FERRARI, 2020). 
Relacionando-se o índice de letalidade a OMS em fevereiro trouxe dados representando que dos infectados sem comorbidade associada apenas $1,4 \%$ morreu, já nos pacientes com alguma patologia cardiovascular esse índice chegou a 13, 2\% (COSTA I., et al 2020). No entanto nesse período o índice de letalidade geral estava a 3,8\% porém, de acordo com Brasil 2020, até o dia o6 de abril do mesmo ano no mundo verificou-se a taxa de letalidade pelo vírus em 5,6\% e no Brasil 4,6\%, o que propõe um aumento nessa porcentagem após a atualização. (COSTA J., et al 2020).

No entanto, há incertezas sobre a estimativa do número real de pessoas infectadas o que afeta diretamente a identificação de casos novos mesmo que sejam leves ou assintomáticos, dados estes que são cruciais para o controle da transmissão (FERRARI, 2020).

Coincidente com o aumento no número de idosos ocorre também à transição epidemiológica que leva ao aumento no índice de doenças crônicas como patologias cardiovasculares, neoplasias, doenças do aparelho respiratório e diabetes melito. Essas comorbidades são relacionadas ao grupo de risco do coronavírus já que a taxa de mortalidade entre pessoas com alguma doença crônica é nove vezes maior. (COSTA J., et al 2020).

De acordo com Ferrari 2020, dados comprovam que dos pacientes infectados pelo novo coronavírus as complicações mais comuns foram: a lesão cardíaca aguda 7,2\%, choque $8,7 \%$ e arritmia $16,7 \%$. Do mesmo modo ainda foi apontado que doenças cardiovasculares e hipertensão foram associadas a uma alta letalidade.

Costa I. et al 2020, relata que o vírus causa dano ao sistema cardiovascular por meio de vários mecanismos como a própria replicação viral, que provoca lesão direta, ou por complicações advindas da resposta inflamatória, alta demanda metabólica e baixa reserva cardíaca, além de reação trombótica desencadeada pela doença.

O mesmo autor ressalta que após o início da infecção viral o organismo como resposta leva a uma inflamação sistêmica que pode ser observada a partir da elevação de marcadores inflamatórios como proteína $\mathrm{C}$ reativa (PCR), procalcitonina, dímero-d, interleucina-6 (IL-6), ferritina e desidrogenase láctica (DHL). Além do mais ainda manifesta-se sinais de injúria miocárdica com o aumento da troponina maior que o percentil 99 e NT-proBNP que leva a miocardite, insuficiência cardíaca aguda, arritmias e trombose. 
Complicações cardiovasculares estas que prejudicam o combate do corpo contra o vírus podendo levar a choque, falência de órgãos e morte.

De acordo com Borges, Jesus, Moura 2019, as troponinas são proteínas presentes nas células musculares que formam um complexo cálcio-dependente com a miosina e actina dando origem à contração muscular. A subdivisão Troponina I é exclusiva ao tecido cardíaco e não detectável no sangue de pessoas saudáveis, por isso seu aparecimento passa a ser um marcador de lesão miocárdica e para casos de disfunção do músculo cardíaco que deve ser atentamente monitorado.

Tratando-se ainda de alterações cardíacas a miocardite ganha destaque sendo relacionada à falência cardíaca aguda nos pacientes infectados pelo coronavírus. É caracterizada pela inflamação decorrente de agressão infecciosa podendo acometer estruturas do coração causando pericardite ou vasculite coronariana. Relacionando-se a covid-ıg foi retratada a miocardite fulminante com rápida evolução e disfunção ventricular associada a edema miocárdico difuso. (CALDEIRA et al 2015; COSTA I., et al 2020).

Segundo Costa J., et al 2020, pacientes com Covid-19 principalmente em casos graves, possuem risco elevado de desenvolver tromboembolismo venoso visto que possuem parâmetros anormais de coagulação e há uma diminuição de sua mobilidade. Uma justifica é que graças ao aumento da resposta inflamatória pode ocorrer disfunção endotelial e elevação da atuação pró-coagulante, fatores que se associam a menor quantidade de oxigênio circulante desencadeando a formação de um trombo.

O vírus liga-se pela proteína spike ao receptor de ECA 2 entrando assim na célula hospedeira favorecendo lesão pulmonar e consequentemente como o coração apresenta níveis elevados de ECA 2 pode-se ocorrer lesões graves neste órgão. (COSTA I., et al 2020).

Em um estudo realizado por Guo et al 2020, o autor apontou a existência de outra relação entre o índice de mortalidade pela Covid-ı́ e as doenças cardiovasculares e hipertensão baseando-se que essas doenças podem ser relacionadas ao sistema reninaangiotensina pois a ECA 2 é desregulada nestas patologias. Aponta ainda que as doenças cardiovasculares e a inibição farmacológica do sistema renina-angiotensina aumentam a quantidade de ECA 2 e pode aumentar potencialmente a virulência, no entanto ainda não existem estudos que comprovam isso. 
ECA 2 está relacionada ao sistema imune e regula negativamente o sistema reninaangiotensina pela inativação da angiotensina-2. Apesar de serem homólogas a enzima conversora de angiotensina (ECA) e a ECA 2 possuem sítios de ativação e ações diferentes, por isso a inibição da ECA não tem efeito direto sobre a ECA 2. Em contrapartida sugere-se que a angiotensina II seja a responsável pelos danos cardíacos do coronavírus e que consequentemente a administração da ECA 2 normaliza esses níveis. (COSTA I., et al 2020).

No entanto, vale à pena ressaltar que esses medicamentos inibidores da ECA ou bloqueadores do receptor da angiotensina II são de uso contínuo no tratamento das doenças citadas acima e a retirada dos mesmos pode causar piora clínica por agravamento dessas condições já preexistentes ou causar finais graves como acidente vascular encefálico e morte (SANTOS et al 2020). Costa I., et al 2020, ressalta ainda que em casos graves de Covid-19 deve-se avaliar individualmente a função renal e estabilidade hemodinâmica do paciente para decidir em relação a suspensão ou manutenção desses fármacos.

\section{CONCLUSÃO}

Conclui-se então que a COVID-ı́ é uma doença grave e apresenta elevado índice de disseminação, principalmente em pacientes com doenças crônicas. Portanto lavar as mãos frequentemente, usar álcool em gel, fazer o uso da máscara de forma correta e evitar ambientes aglomerados, é importante na redução da propagação do vírus.

Porém, pacientes que tem doença cardiovascular infectados por COVID-I9 podem apresentar prognóstico pior, de acordo com os estudos verificados, o que revela a confirmação da primeira hipótese do estudo, tendo como principais complicações arritmia, lesão cardíaca, aumento dos fatores pró-coagulantes, miocardite, insuficiência cardíaca aguda e trombose.

Há de se entender que pontuar situações recorrentes da COVID-19 já é algo comumente causal, de modo que, os dados refletem tal poder de contaminação e elevada taxa de mortalidade. Por conta, notamos a intensa conduta de distanciamento, uma vez que, pessoas portadoras de alguma situação cardiovascular passam a ser temerária por uma ideia de complicações sugestivas e prolongadas, deixando sequelas, para a continuidade da vida. 
As evidências atuais já mostram a necessidade de atenção especial aos pacientes do grupo de risco e a importância de um manejo adequado destes relacionado às complicações cardiovasculares desencadeadas pelo vírus, com rápida identificação através de um olhar clínico e implementação de um tratamento adequado. Competências estas adquiridas através do conhecimento da relação entre o coronavírus e o sistema cardiovascular. Tal conduta, promove a vida, proporciona qualidade de vida e avança para recuperação da rotina casual.

\section{REFERÊNCIAS}

I. ASKIN, L.; TANRIVERDI, O.; ASKIN, H. S. O efeito da Doença de Coronavírus 2019 nas Doenças Cardiovasculares. Sociedade Brasileira de Cardiologia; Arq Bras Cardiol. 2020, II4(5): 817-822. Turquia.

2. BRASIL, Ministério da Saúde. Brasil confirma primeiro caso da doença. Rio de Janeiro, DF: Ministério da Saúde; 2020. [citado 22 mar. 2020]. Disponível em: 〈https://www.saude.gov.br/noticias/agencia-saude/46435-brasil-confirma-primeiro-casode-novo-coronavirus>.

3. BORGES, L. P., de JESUS, R. C. S., \& MOURA, R. L. (2019). Utilização de biomarcadores cardíacos na detecção de infarto agudo do miocárdio. Revista Eletrônica Acervo Saúde, II(13), e940. https://doi.org/ro.25248/reas.e940.2019.

4. CAldeIRA, D.; LOPES, L. R.; CARNEIRO, A. V.; COSTA J. Cochrane Corneradministração de corticosteróides para miocardite de etiologia viral. Revista Portuguesa de Cardiologia. Vol 34, Issue I. Janeiro 2015, pag. 65-67.

5. COSTA, I. B. S. da; BITTAR, C. S.; RIZK S. I.; FILHO, A. E. A. de; SANTOS, K. A. Q.; MACHADO, T. I. V.; ANDRADE, F. T. A. de; GONZÁlEZ, T. B.; ARÉVAlO, A. N. G.; ALMEIDA, J. P. de; BACAL, F.; OLIVEIRA, G. M. M. de; LACERDA, M. V. G. de; BARBERAto S. H.; CHAGAS, A. C. P.; ROCHITte, C. E.; RAMIRES, J. A. F.; FILHO, R. K.; HAJJAR, L. A. O Coração e a COVID-ı: O que o Cardiologista precisa saber. Sociedade Brasileira de Cardiologia; Arq Bras Cardiol. 2020, II4(5): 805-8I6. São PauloBrasil.

6. COSTA, J. A.; SILVEIRA, J. A. de; SANTOS, S. C. M.; NOGUEIRA, P. P. Implicações Cardiovasculares em pacientes infectados com Covid-ıg e a importância do isolamento 
social para reduzir a disseminação da doença. Sociedade Brasileira de Cardiologia; Arq Bras Cardiol. 2020, II4(5):834-838. Rio de Janeiro- Brasil.

7. FERRARI, F. Covid-ı: Dados atualizados e sua relação com o Sistema Cardiovascular. Sociedade Brasileira de Cardiologia; Arq Bras Cardiol. 2020; II4(5): 823-826. RS- Brasil.

8. Guo YR, Cao QD, Hong ZS, Tan YY, Chen SD, Jin HJ, et al. The origin, transmission and clinical therapies on coronavirus disease 2019 (COVID-19) outbreak - an update on the status. Mil Med Res. 2020;7(I):II.

9. LIMA, C. M. A. O. de. Informações sobre o novo coronavírus (COVID-19). Colégio Brasileiro de Radiologia e Diagnóstico por Imagem; Radiol Bras. 2020 Mar/Abr; 53(2):V-VI. ıo. MARCONI, M. A.; LAKATOS, E. M. Metodologia científica. São Paulo: Atlas, 2013.

II. PRODANOVI, C. C.; FREITAS E. C. Metodologia do Trabalho Científico: Métodos e Técnicas da Pesquisa e do Trabalho Acadêmico. $2^{\circ}$ edição. Novo Hamburgo: Editora Feevale, 2013.

12. SANTOS, B. Jr dos; REY, H. C. V.; AGUIAR C. M.; TURA, B. R. Análise de associação entre fármacos que aumentam a expressão de ECA2 e os desfechos de pacientes com COVID-19: uma Revisão rápida. Instituto Nacional de Cardiologia, RJ. 2020.

13. STRABElli, T. M. V; UIP D. E. Covid-ra e o Coração. Sociedade Brasileira de Cardiologia; Arq Bras Cardiol. 2020, II4(4):598-60o. Rio de Janeiro, Brasil. 